\title{
Synthesis of Silica using Silk Sericin without Hydrolysis of Tetraethyl Orthosilicate
}

\author{
Ji Young Lee ${ }^{1}$, and Ki Hoon Lee $2,3,4 *$ \\ ${ }^{1}$ National Instrumentation Center for Environmental Management, Seoul National University, Seoul 151-921, Korea \\ ${ }^{2}$ Department of Biosystems \& Biomaterials Science and Engineering, Seoul National University, Seoul 151-921, Korea \\ ${ }^{3}$ Center for Food and Bioconvergence, Seoul National University, Seoul 151-921, Korea \\ ${ }^{4}$ Research Institute for Agriculture and Life Sciences, Seoul National University, Seoul 151-921, Korea
}

\section{Abstract}

In this study, the effect of sericin on synthesis of the silica was investigated. Using the mixture of sericin solution and tetraethyl orthosilicate (TEOS), it was confirmed that silica could be synthesized in the presence of sericin, which was verified by thermal gravimetric analysis (TGA), Fourier-transformed infrared spectrometer (FT-IR) and nuclear magnetic resonance spectrometer (NMR) analysis. The TGA and FT-IR data revealed that silica-sericin complex was formed as a final product. Based on the TGA result, the content of silica and sericin in the complex would be 87 and 13\%, respectively. The degree of silica condensation was higher than the natural biosilica. It could be concluded that sericin can induce the synthesis of silica directly from TEOS, which is similar to silicatein from marine sponges.

(C) 2013 The Korean Society of Sericultural Sciences

Int. J. Indust. Entomol. 27(2), 298-302 (2013)

Received : 1 Dec 2013

Accepted : 15 Dec 2013

Keywords:

Silk sericin,

Silica,

Silicatein,

Biomineralization,

Biosilicification

\section{Introduction}

Silica is the second abundant element in the biosphere and many organisms utilize it as a structural component (Rupcich et $a l ., 2003)$. Diatom is the one of the example, which synthesizes silica and protects their cell structure with it (Fuhrmann et al., 2004). Marine sponges also synthesize silica and their spicules are made of it (Cha et al., 1999). These organisms condense silicic acid into silica, and the process is mediated by several proteins.

Silaffin is a protein from in diatoms and is known to facilitate the silica synthesis (Kröger et al., 2001). Moreover, it can control the morphology of the synthesized silica (Sumper et al., 2006). On the other hand, silicatein which derives from marine sponges is an enzyme that catalyzes the silica synthesis directly from the silica precursor (Shimizu et al., 1998). In both proteins, serine plays an important role in the silica synthesis. Silaffin has high content of serine which is phosphorylated by post-translational modification (Kröger et al., 2002). In the case of silicatein, serine is located at the active center (Cha et al., 2000). This gave us an idea to use sericin for the silica synthesis because sericin has also high content of serine.

Sericin is a minor protein that is secreted by the silkworm. It bonds two brins of fibroin fiber together and make able to maintain the shape of cocoon. Sericin is usually discarded by the degumming process but could be used as new source of biopolymer, because it is easy to extract and able to get in

\section{${ }^{*}$ Corresponding author.}

Ki Hoon Lee

Department of Biosystems \& Biomaterials Science and Engineering, Seoul National University, 1 Gwanak-ro, Gwanak-gu, Seoul 151-921, Korea

Tel: +82-2-880-4625 / FAX: +82-2-873-2285

E-mail: prolee@snu.ac.kr 
large quantities. Currently sericin is used as an ingredient of cosmetics (Kim et al., 2009) and new application are found in pharmaceutical, polymeric, and biomedical field (Zhaorigetu et al., 2001; Kwak et al., 2013; Oh et al., 2011). Previously, sericin has been used to induce the biomineralization of hydroxy apatite (Takeuchi et al, 2008). In this study, we used sericin in order to synthesize the silica. The synthesis of silica was verified with various analytical methods.

\section{Materials and Methods}

\section{Materials}

Silk cocoon was obtained from Hung Jing Co., LTD. (Seoul, Korea). All other chemicals were purchased from Sigma-Aldrich LTD. (Yongin, Korea).

\section{Preparation of hot-water extracted sericin solution}

Silk cocoons were boiled with distilled water using an autoclave at $120^{\circ} \mathrm{C}$ for $1 \mathrm{~h}$. The solution was filtered with a nonwoven filter in order to remove the remaining silk fibers. The solution was freshly made every time before the experiment. The final concentration of sericin was $1 \%(\mathrm{w} / \mathrm{v})$.

\section{Synthesis of silica using sericin}

The synthesis of silica was performed by mixing tetraethyl orthosilicate (TEOS) and sericin solution. More precisely, 500 $\mu \mathrm{L}$ of TEOS and $500 \mu \mathrm{L}$ of sericin solution were added in a Eppendrof tube, and it was shaken vigorously with an orbital shaker. The tube was incubated at room temperature without further stirring. After $1 \mathrm{wk}, 400 \mu \mathrm{L}$ of ethanol was added to the mixture and centrifuged at $10,000 \mathrm{~g}$ for $1 \mathrm{~min}$ in order to precipitate the reactant. The precipitate was further washed with ethanol 3 times. The collected precipitate was dried in a vacuum chamber for $36 \mathrm{~h}$ in order to remove residual ethanol.

\section{Analysis of precipitate}

The formation of silica was verified by thermal gravimetric analysis (TGA, Q-5000 IR, TA-Instrument, USA), Fourier transformed-infrared spectrometer (FT-IR, MIDAC, Japan) and ${ }^{29}$ Si nuclear magnetic resonance spectrometer (NMR, AVANCE, Bruker, Germany). The heating rate of TGA was $10^{\circ} \mathrm{C} / \mathrm{min}$ and the data in the range of $100-600^{\circ} \mathrm{C}$ were collected under nitrogen gas purging. In the case of FT-IR, the spectrum was obtained from $\mathrm{KBr}$ method after 24 scans and the resolution was $4 \mathrm{~cm}^{-1}$. Solid-state ${ }^{29}$ Si MAS NMR spectra were acquired on a DSX400 NMR spectrometer (Bruker, Germany) operating at 79.5 $\mathrm{MHz}$. Detailed conditions were as follows: spinning rate, 3.5 $\mathrm{kHz}$; pulse length, $4.2 \mu \mathrm{s}$; recycle delay, $30 \mathrm{~s}$. Field emission scanning electron microscope (FE-SEM, SUP-RA55 VP, Carl Zeiss, Germany) was employed to observe the microscopical morphology of the precipitate.

\section{Results and Discussion}

We prepared sericin solution by the hot-water extraction method. Sericin solution was added to TEOS and left in the chamber without stirring for $1 \mathrm{wk}$ at room temperature. The TEOS and the sericin solution did not mix each other (Fig. 1a), and a white precipitate was formed only at the interface between the TEOS and the sericin solution. In order to improve the precipitation, we stirred the reaction tube vigorously. A dispersion of the two liquid was formed in the sericin layer and maintained through the incubation time. The white precipitate was grown in the sericin solution layer during $1 \mathrm{wk}$ of incubation (Fig. 1b). Fig. 1c shows the final precipitate obtained after washing and drying.

In order to verify the synthesis of silica, we first performed TGA analysis. While sericin decomposes over $200^{\circ} \mathrm{C}$, the weight loss of precipitates was about $15 \%$ even at $600^{\circ} \mathrm{C}$ indicating the formation of silica (Fig. 2). In the case of the precipitate, there was a significant loss of weight between $200 \sim 400^{\circ} \mathrm{C}$ which was the same temperature range that the thermal degradation of sericin occurs. Therefore, the precipitate might be a complex of silica and sericin. Based on the TGA results, the weight percent of silica and sericin in the complex would be 87 and 13\%, respectively.

The formation of silica-sericin complex could be also verified by the ATR-FTIR results (Fig. 3). The asymmetric stretch, symmetric stretch and bending vibration of Si-O-Si at 1100, 800 


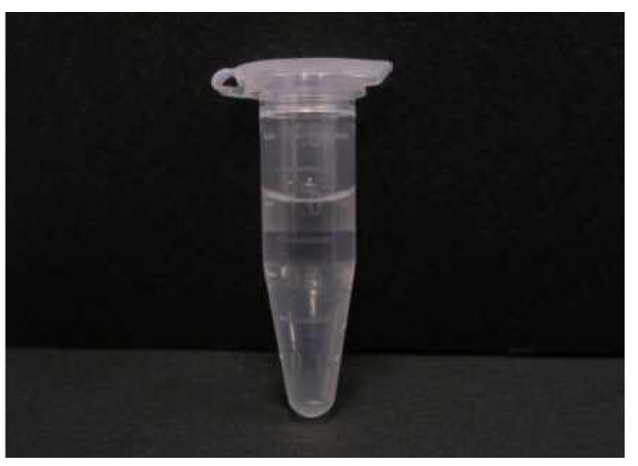

(a)

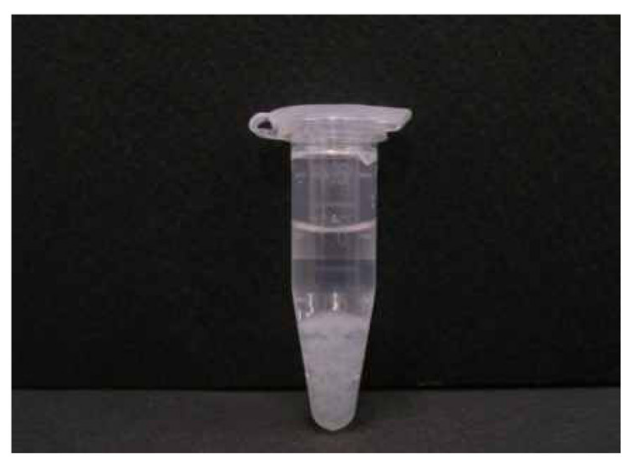

(b)

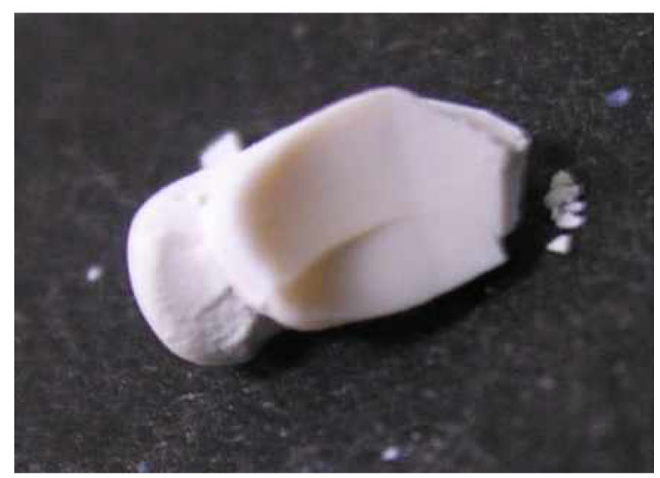

(c)

Fig. 1. Optical images of TEOS and sericin solution mixture before mixing (a) and after 1 wk of incubation (b). The final precipitate after washing and drying is shown in (c).

and $450 \mathrm{~cm}^{-1}$, respectively, could be observed in the ATR-FTIR spectrum (Siuzdak et al., 1999). At the same time, a characteristic peak of amide I $\left(1650 \mathrm{~cm}^{-1}\right)$ and amide II $\left(1530 \mathrm{~cm}^{-1}\right)$ could be observed (Teramoto et al., 2005). This result also indicates that the precipitate is a complex of silica and sericin.

The synthesis of silica can be also verified by the NMR. Generally, $\mathrm{Q}^{n}$ notation $\left(\mathrm{Q}^{1}, \mathrm{Q}^{2}, \mathrm{Q}^{3}\right.$ and $\left.\mathrm{Q}^{4}\right)$ is used to identify the environment of silicon atom, and $n$ indicates the number

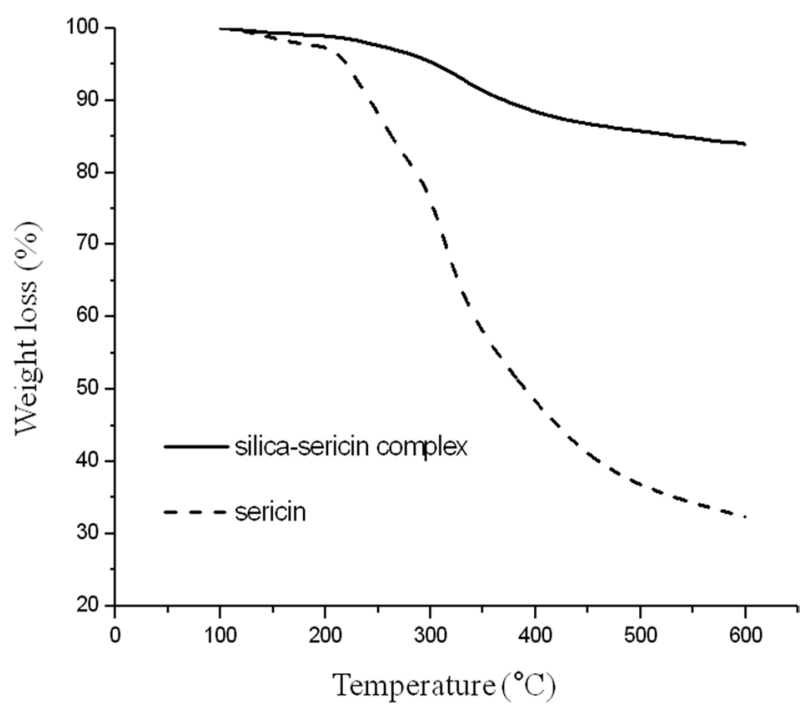

Fig. 2. TGA curves of silica-sericin complex and sericin.

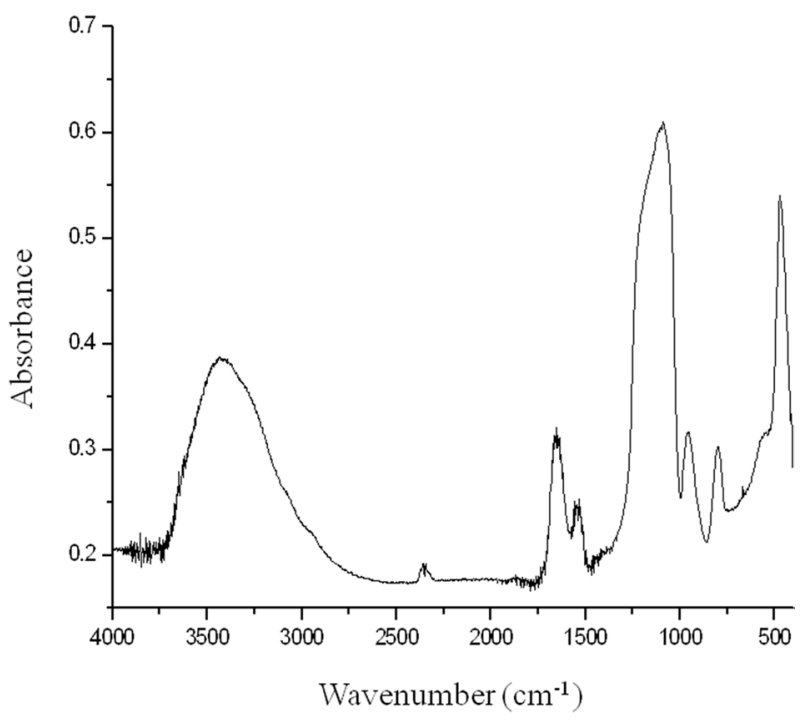

Fig. 3. FT-IR spectrum of silica-sericin complex.

of siloxane bonds connecting a silicon atom with other silicon atoms via oxygen bridges. In NMR, the resonance signal of $\mathrm{Q}^{2}$, $\mathrm{Q}^{3}$ and $\mathrm{Q}^{4}$ appears at $\delta \approx-92,-101$ and $-110 \mathrm{ppm}$, respectively (Bertermannm et al., 2003; Cong et al., 1993). All 3 peaks could be found in the NMR spectrum indicating the synthesis of silica (Fig. 4). The $\mathrm{Q}^{4} / \mathrm{Q}^{3}$ ratio indicates the degree of silica condensation, and it was 2.28 which are higher than the natural biosilica (Table 1).

Fig. 5 shows the FE-SEM image of silica-sericin complex. It had a fractal structure where sphere-like particles having tens of nanometer size are agglomerated into large and irregular shapes. 


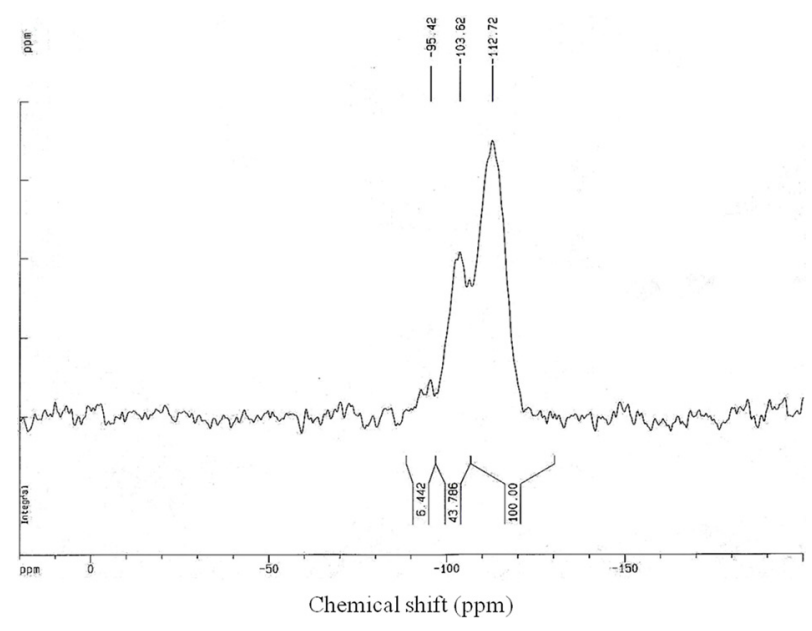

Fig. 4. Solid phase ${ }^{29} \mathrm{Si}$ MAS NMR spectrum of silica-sericin complex.

Table 1. Quantitative analysis of $Q^{2}, Q^{3}$, and $Q^{4}$ peaks in silicasericin complex.

\begin{tabular}{|ccccc|}
\hline & $Q^{4}$ & $Q^{3}$ & $Q^{2}$ & $Q^{4} / Q^{3}$ \\
\hline Natural biosilica $^{a}$ & 100 & 53.13 & 3.13 & 1.9 \\
\hline Silica-sericin complex & 100 & 43.77 & 24.82 & 2.28 \\
\hline
\end{tabular}

a: from Bertermannm et al. (2003)

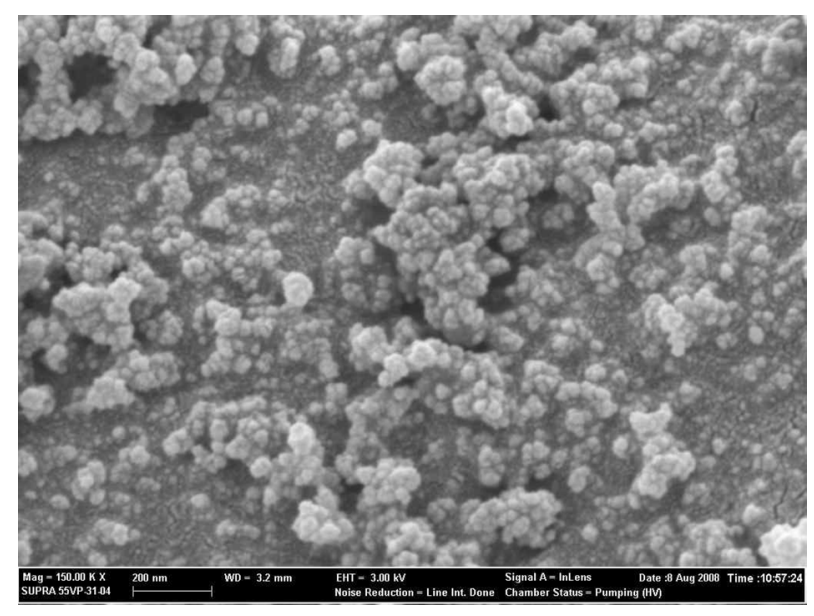

Fig. 5. FE-SEM image of silica-sericin complex. $(\times 15000)$

Generally, TEOS is hydrolyzed under acidic or basic condition to in order to synthesize silica through sol-gel process. However, the present study shows that silica could be synthesized directly from TEOS without any hydrolysis. It seems that the role of sericin during silica formation is similar to silicatein. Further application of the synthesized silica nano- and microparticles in biomedical field is under investigation. Expected area is drug delivery and tissue engineering where silicatein is currently applied (Schröder et al., 2007).

\section{Acknowledgement}

This research was supported by Basic Science Research Program through the National Research Foundation of Korea(NRF) funded by the Ministry of Education(NRF-2009-0072366).

\section{References}

Bertermannm R, Kröger N, Tacke R (2003) Solid-state ${ }^{29}$ Si MAS NMR studies of diatioms: structural characterization of biosilica deposits. Anal Bioanal Chem 375, 630-634.

Cha JN, Shimizu K, Zhou Y, Christiansen SC, Chemlka BF, Stucky GD, Morse DE (1999) Silicatein filaments and subunits from a marine sponge direct the polymerization of silica and silicones in vitro. $\mathrm{P}$ Natl Acd Sci USA 96, 361-365.

Cha JN, Stucky GD, Morse DE, Demlng TJ (2000) Biomimetic synthesis of ordered silica structures mediated by block copolypeptides. Nature 403, 289-292.

Cong X, Kirkpatrick RJ (1993) ${ }^{29}$ Si MAS NMR spectroscopic investigation of alkali silica reaction product gels, Cement Concrete Res 23, 811-823.

Fuhrmann T, Landehr S, Rharbi-kuchi ME, Sumper M (2004) Diatom as living photonic crystals. Appl Phys B 78, 257-260.

Kim MK, Oh H, Lee JY, Lee JY, Lee KH (2009) Enzymatic Hydrolysis of Silk Sericin and its Anti-oxidative Effect. J Soc Cosmet Scientists Korea 35, 135-141.

Kröger N, Deutzmann R, Sumper M (2001) Silica-precipitating peptide from diatoms. J Biol Chem 276, 26066-26070.

Kröger N, Lorenz S, Brunner E, Sumper M (2002) Self-assembly of highly phosphorylated silaffins and their function in biosilica morphogenesis. Science 18, 584-586.

Kwak HW, Yang YS, Kim MK, Lee JY, Yun HS, Kim MH, Lee KH (2013) Chromium(VI) adsorption behavior of silk sericin bead. Int J Indust Entomol 26, 47-53.

Oh H, Kim MK, Lee KH (2011) Preparation of sericin microparticles by electrohydrodynamic spraying and their application in drug delivery. Macromol Res 19, 266-272.

Rupcich N, Goldstein A, Brennan JD (2003) Optimization of sol-gel 
formulations and surface treatments for the development of pin-print protein microarrays. Chem Mater 15, 1803-1811.

Schröder HC, Brandt D, Scholoßmacher U, Wang X, Tahir MN, Tremel W, Belikov SI, Müller WEG (2007) Enzymatic production of biosilica glass using enzymes from sponges: basic aspects and application in nanobiotechnology (material sciences and medicine). Naturwissenshchaften 94, 339-359.

Shimizu K, Cha J, Stucky GD, Morse DE (1998) Silicatein a: Cathepsin L-like protein in sponge biosilica. P Natl Acd Sci USA 95, 62346238.

Siuzdak DA, Kenneth A, Mauritz (1999) Surlyn ${ }^{\circledR} /[$ Silicon Oxide] hybrid materials. 2. physical properties chacterization. J Polym Sci B Polym Phys 37, 143-154.
Sumper M, Brunner E (2006) Learning from diatoms: nature's tools for the production of nanostructured silica. Adv Funct Mater 16, 17-26.

Takeuchi A, Ohtsuki C, Kamitakahara M, Ogata S, Miyazaki T, Tanihara M (2008) Biomimetic deposition of hydroxyapatite on a synthetic polypeptide with $\beta$-sheet structure in a solution mimicking body fluid. J Mater Sci 17, 378-393.

Teramoto H, Miyazawa M (2005) Molecular orientation behavior of silk sericin film as revealed by ATR infrared spectroscopy. Biomacromolecules 6, 2049-2057.

Zhaorigetu S, Sasaki M, Watanabe H, Kato N (2001) Supplemental silk protein, sericin, suppresses colon tumorigenesis in 1,2 z-dimethylhydrazine-treated mice by reducing oxidative stress and cell proliferation. Biosci Biotechnol Biochem 65, 2181-2186. 